\title{
Development and Performance Assessment of the High-Performance Shrinkage Reducing Agent for Concrete
}

\author{
Hyung Sub Han, ${ }^{1}$ Jong Kyu Kim, ${ }^{2}$ and Yong Wook Jung ${ }^{3}$ \\ ${ }^{1}$ R\&D Center, Dongnam Co., Ltd., Gyeonggi-do, Republic of Korea \\ ${ }^{2}$ Department of Civil Engineering, Kyungnam University, Changwon, Republic of Korea \\ ${ }^{3}$ Advanced Construction Materials Testing Center, Keimyung University, Daegu, Republic of Korea
}

Correspondence should be addressed to Jong Kyu Kim; jongkim@kyungnam.ac.kr and Yong Wook Jung; jyw@kmu.ac.kr

Received 27 April 2016; Revised 20 July 2016; Accepted 15 August 2016

Academic Editor: Hossein Moayedi

Copyright (C) 2016 Hyung Sub Han et al. This is an open access article distributed under the Creative Commons Attribution License, which permits unrestricted use, distribution, and reproduction in any medium, provided the original work is properly cited.

\begin{abstract}
To develop a high-performance shrinkage reducing agent, this study investigated several shrinkage reducing materials and supplements for those materials. Fluidity and air content were satisfactory for the various shrinkage reducing materials. The decrease in viscosity was the lowest for glycol-based materials. The decrease in drying shrinkage was most prominent for mixtures containing glycol-based materials. In particular, mixtures containing G2 achieved a 40\% decrease in the amount of drying shrinkage. Most shrinkage reducing materials had weaker level of compressive strength than that of the plain mixture. When $3 \%$ triethanolamine was used for early strength improvement, the strength was enhanced by $158 \%$ compared to that of the plain mixture on day 1 ; enhancement values were $135 \%$ on day 7 and $113 \%$ on day 28 . To assess the performance of the developed high-performance shrinkage reducing agent and to determine the optimal amount, $2.0 \%$ shrinkage reducing agent was set as $40 \%$ of the value of the plain mixture. While the effect was more prominent at higher amounts, to prevent deterioration of the compressive strength and the other physical properties, the recommended amount is less than $2.0 \%$.
\end{abstract}

\section{Introduction}

Concrete is an outstanding construction material due to its outstanding strength and durability [1]. The affordable cost of concrete makes it one of the most widely used materials in construction. Despite these advantages, concrete often develops cracks, which cause not only deterioration in strength and durability but also economic loss due to the need for more maintenance [2]. These are issues that must be resolved for concrete structures [3].

The causes of cracks in concrete can be largely divided into structural factors [4], material factors [5], amount factors [6], and environmental factors [7]. A significant portion of the problem is taken up by drying shrinkage, which occurs with the drying of surplus water among the unit content of water required for concrete manufacturing. Cracks caused by drying shrinkage are considered inevitable in concrete structures. When drying shrinkage occurs, cracks form in concrete structures due to the imbalance of contractile force and the binding force of concrete [8].
One effective method of reducing cracks caused by drying shrinkage is to reduce the unit content of water, but this achieves only a limited effect [9]. As such, common methods employed include the introduction of chemical prestress using an expansion material [10] and the use of an organic shrinkage reducing agent $[11,12]$. Shrinkage compensation using an expansion material involves an unclear mechanism, and the inconsistent expansion makes it less useable [13]. In addition, most shrinkage reducing agents are produced overseas, and local products tend to have weaker performance and to negatively affect the strength and durability of concrete. The domestic production of high-performance shrinkage reducing agents is essential to minimize economic loss arising from the dependency on expensive product manufactured overseas.

For this domestic production of shrinkage reducing agents, this study selected a total of seven materials: three alcohol-based materials (A1, A2, and A3), two glycol-based materials (G1, G2), animal fatty acids (AF), and vegetable fatty acids (VF). A Japanese shrinkage reducing agent (JP) 
was compared to the seven shrinkage reducing materials. In surface tension and mortar applications, three alcoholbased materials and two glycol-based materials were selected based on performance assessment in terms of flow, strength, and drying shrinkage. After applying the five shrinkage reducing materials to concrete, one material was eventually selected and processed into a high-performance shrinkage reducing agent for concrete. For performance assessment, the shrinkage reducing agent was applied to concrete and evaluated for various properties including slump, air content, compressive strength, and drying shrinkage length change.

\section{Experimental Plan and Methods}

2.1. Experiment Overview. This study performed concrete application tests on five shrinkage reducing materials, selected based on a literature review, theoretical examination, and surface tension and mortar applications. One shrinkage reducing material was eventually selected. Through performance enhancement, the selected material was used to produce a high-performance shrinkage reducing agent for concrete. The experimental plan is presented in Table 1 .

2.2. Materials. To develop a high-performance shrinkage reducing agent for concrete, a mortar test was used to select three alcohol-based and two glycol-based materials. The physical properties and the molecular structures of the selected shrinkage reducing materials are shown in Tables 2 and 3 .

The shrinkage reducing materials in Table 2 were applied to concrete, and the best material was selected to be processed into the shrinkage reducing agent. For performance enhancement of the selected material, $\mathrm{NN}\left(\mathrm{NaNO}_{3}\right)$, TEA (triethanolamine), and CF (calcium formate) were used as early strength materials. Their physical properties are shown in Table 4.

A high-performance shrinkage reducing agent for concrete was developed by applying the early strength materials shown in Table 3 to the selected shrinkage reducing material. The developed shrinkage reducing agent was applied to concrete for performance verification. Portland cement Type 1 and refined fly ash were used. The properties of cement and fly ash are presented in Tables 5 and 6, respectively. River sand and crushed sand were mixed at a ratio of $5: 5$ to be used as fine aggregate. The maximum size of the coarse aggregate was $25 \mathrm{~mm}$. The physical properties of both fine and coarse aggregates are given in Table 7.

2.3. Experimental Methods. Concrete tests were performed to analyze and assess the five shrinkage reducing materials. Aggregates and binders were mixed for 30 seconds using a shaft mixer. The shrinkage reducing materials, early strength materials, and admixtures were mixed for 90 seconds. Tests for slump and air content of fresh concrete employed the pressure method and were conducted in accordance with the KS F 2402 Method of testing for slump of concrete and the KS F 2421 Method of testing for air content of fresh concrete. To examine the effects of hardening on the concrete properties,

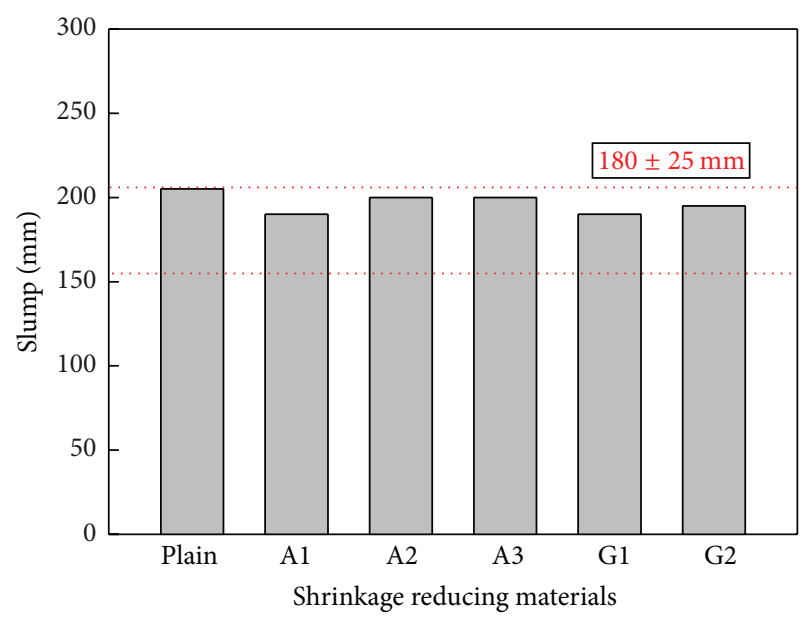

FIGURE 1: Relationship between the slump and the shrinkage reducing material.

compressive strength and drying shrinkage length change were measured. Compressive strength was measured using a $\varnothing 100 \times 200 \mathrm{~mm}$ cylindrical specimen, as specified in KS F 2403 and in accordance with KS F 2405. The drying shrinkage length change of concrete was measured by installing a strain gauge at the center of the $100 \times 100 \times 400 \mathrm{~mm}$ rectangular mold.

\section{Results and Analysis}

3.1. Properties of Concrete in Relation to Type of Shrinkage Reducing Materials. To develop a high-performance shrinkage reducing agent for concrete, this study performed concrete application tests to analyze the properties of three alcohol-based and two glycol-based shrinkage reducing materials, selected through surface tension and mortar tests. To analyze the effects of the various shrinkage reducing materials on the slump and air content of concrete, the shrinkage unit powder content levels were set at 0 and $2 \%$. The effects on compressive strength and drying shrinkage length change after hardening were analyzed, and the material exhibiting the best performance was selected to be developed into the shrinkage reducing agent.

In Figure 1, it can be seen that all shrinkage reducing materials satisfied the target slump of $180 \pm 25 \mathrm{~mm}$, indicating that the fluidity of concrete is not influenced by the type of material. However, the slight decrease in viscosity shows that material separation characteristics must be considered when selecting the shrinkage reducing material.

The relationship between air content and shrinkage reducing material can be precisely seen in Figure 2 . The plain mixture satisfied the target air content at 5.1\%; all other materials fell in the target range of $4.5 \pm 1.5 \%$. The shrinkage reducing materials selected in this study did not have any significant effect on the air content. The alcohol-based mixtures showed a slight decrease in air content compared to the plain mixture; this can be traced to the antifoaming mechanism of alcohol-based materials. Mixtures containing 


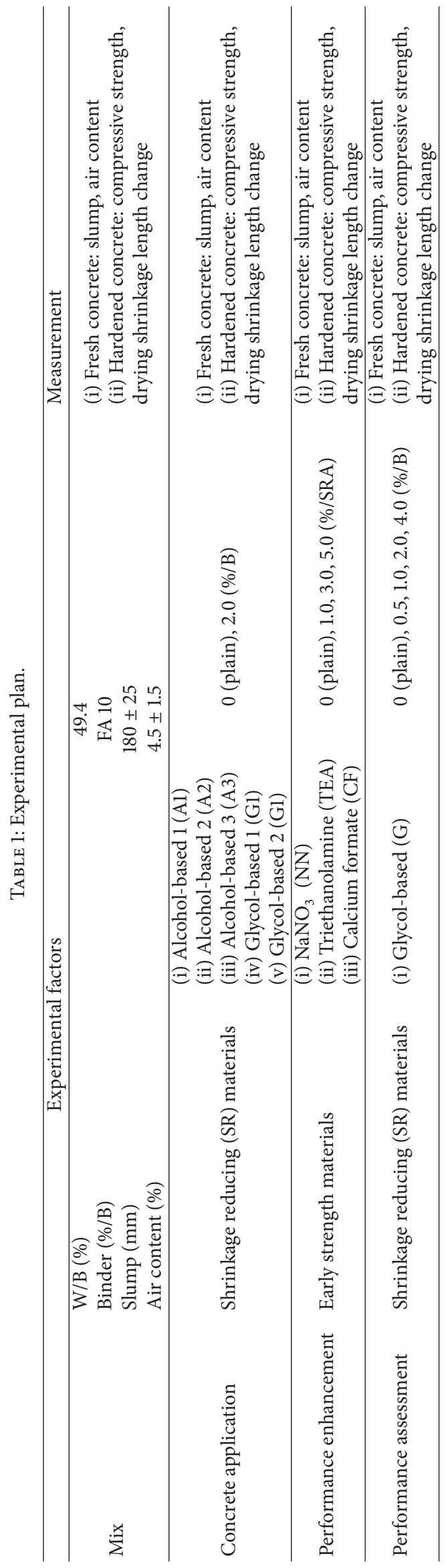


TABLE 2: Physical properties of shrinkage reducing materials in use.

\begin{tabular}{lccc}
\hline Shrinkage reducing materials & Abbreviation & Density $\left(\mathrm{g} / \mathrm{cm}^{3}\right)$ & Color \\
\hline Alcohol-based A & A1 & 0.78 & Colorless \\
Alcohol-based B & A2 & 0.82 & Colorless \\
Alcohol-based C & A3 & 0.79 & Colorless \\
Glycol-based A & G1 & 1.03 & Colorless \\
Glycol-based B & G2 & 0.86 & Colorless \\
\hline
\end{tabular}

TABLE 3: Molecular structures of shrinkage reducing materials in use.

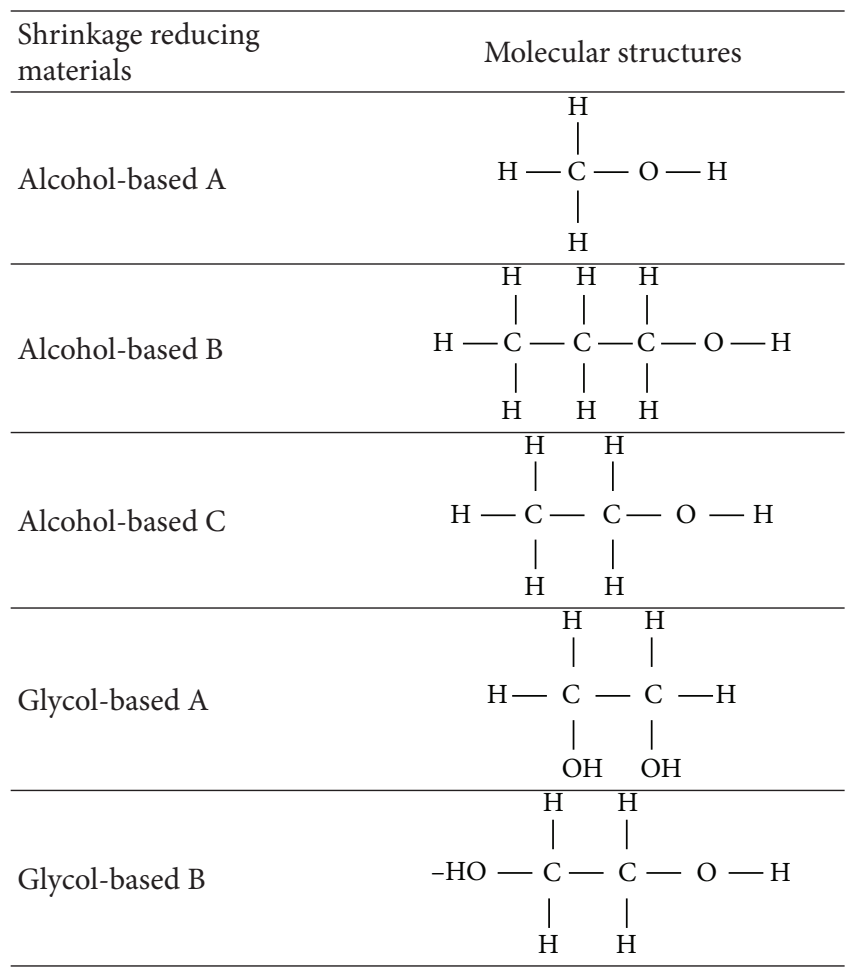

TABLE 4: Physical properties of early strength materials.

\begin{tabular}{lcccl}
\hline Material & Abbreviation & Density $\left(\mathrm{g} / \mathrm{cm}^{3}\right)$ & $\mathrm{pH}$ & State \\
\hline $\mathrm{NaNO}_{3}$ & $\mathrm{NN}$ & 1.29 & 7.48 & \\
Triethanolamine & TEA & 1.48 & 5.23 & Liquid \\
Calcium formate & CF & 1.91 & 7.2 & \\
\hline
\end{tabular}

glycol-based materials had a slight increase in air content, but the difference was negligible.

Figure 3 shows the compressive strength by age for the various shrinkage reducing materials. The plain mixture, without any shrinkage reducing material, had compressive strength of $13.1 \mathrm{MPa}$ on day 3; this value reached a peak of $36.7 \mathrm{MPa}$ on day 56. Most shrinkage reducing materials had weaker compressive strength than that of the plain mixture; early strength enhancement should be employed in order to develop a high-performance shrinkage reducing agent. Mixtures with glycol-based materials showed a slight decrease in compressive strength, equivalent to about $85 \%$ of

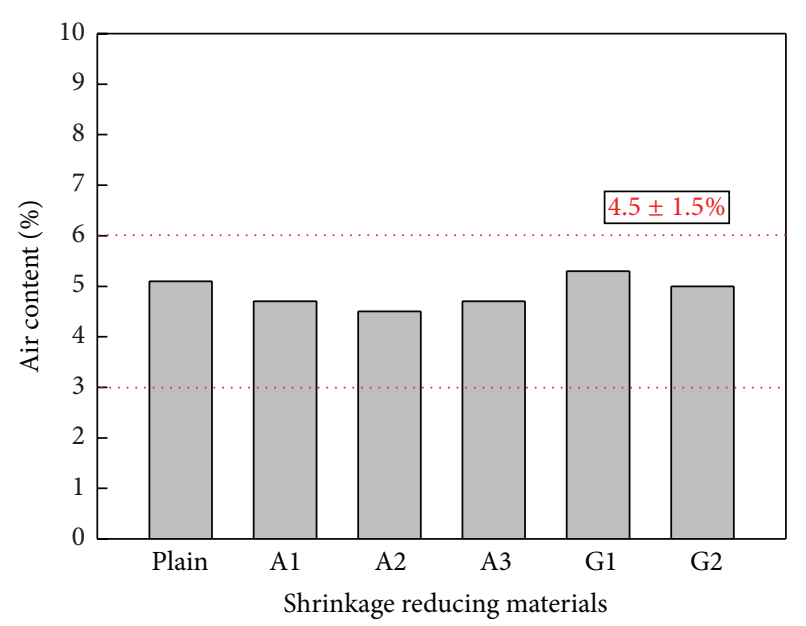

FIGURE 2: Relationship between air content and shrinkage reducing material.

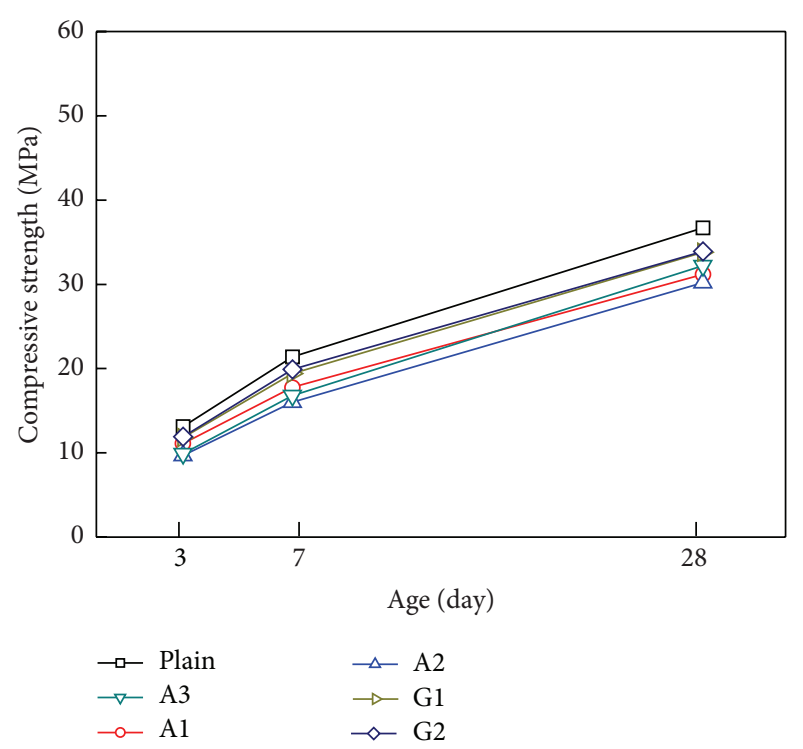

FIGURE 3: Compressive strength by age for various shrinkage reducing materials.

those values for the plain mixtures, but this was higher than that of alcohol-based materials.

Figure 4 shows the drying shrinkage length change by age for various shrinkage reducing materials.

As shown in Figure 4, the plain mixture had drying shrinkage of $760 \times 10^{-6}$ on day 56 . The amount of drying 
TABle 5: Physical/chemical properties of cement.

\begin{tabular}{lcccccc}
\hline \multirow{2}{*}{ Density $\left(\mathrm{g} / \mathrm{cm}^{3}\right)$} & \multirow{2}{*}{ Blaine $\left(\mathrm{cm}^{2} / \mathrm{g}\right)$} & \multicolumn{2}{c}{ Setting time $(\mathrm{min})$} & \multicolumn{3}{c}{ Compressive strength $(\mathrm{MPa})$} \\
& & Initial & Final & 3 days & 7 days & 28 days \\
\hline 3.15 & 3,265 & 210 & 300 & 22.0 & 28.9 & 38.9 \\
\hline
\end{tabular}

TABLE 6: Physical properties of fly ash.

\begin{tabular}{lcccc}
\hline Density $\left(\mathrm{g} / \mathrm{cm}^{3}\right)$ & Blaine $\left(\mathrm{cm}^{2} / \mathrm{g}\right)$ & LOI $(\%)$ & $\mathrm{SiO}_{2}(\%)$ & Moisture $(\%)$ \\
\hline 2.20 & 3850 & 2.50 & 51.3 & 0.10 \\
\hline
\end{tabular}

TABLE 7: Physical properties of aggregates.

\begin{tabular}{llccccc}
\hline \multicolumn{2}{c}{ Aggregates } & Density $\left(\mathrm{g} / \mathrm{cm}^{3}\right)$ & FM & Absorption $(\%)$ & $\begin{array}{c}\text { Unit volume } \\
\text { weight }\left(\mathrm{kg} / \mathrm{m}^{3}\right)\end{array}$ & $\begin{array}{c}0.08 \mathrm{~mm} \text { sieve } \\
\text { passing percentage } \\
(\%)\end{array}$ \\
\hline \multirow{2}{*}{ Fine agg. } & River sand & 2.65 & 2.62 & 1.42 & 1,637 & 2.53 \\
& Crushed sand & 2.70 & 2.94 & 1.50 & 1,692 & 2.68 \\
\hline Coarse agg. & Granite stone & 2.83 & 6.55 & 0.58 & 1,684 & 0.40 \\
\hline
\end{tabular}

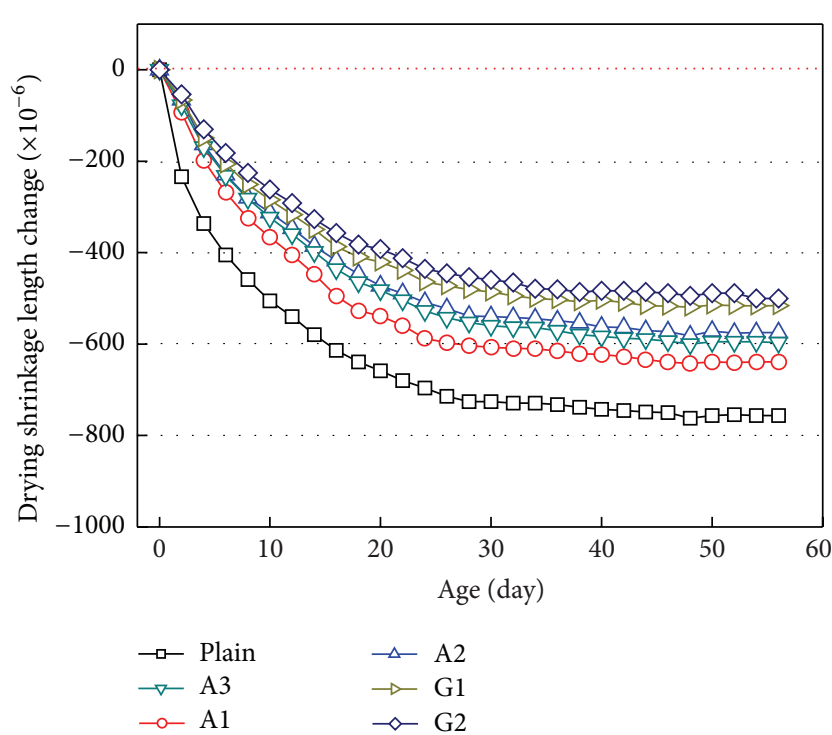

FIGURE 4: Drying shrinkage length change by age for various shrinkage reducing materials.

shrinkage could be reduced by $18 \% \sim 40 \%$ depending on the type of shrinkage reducing material. The decrease in drying shrinkage was most prominent for mixtures containing glycol-based materials. In particular, mixtures containing G2 achieved a $40 \%$ decrease in the amount of drying shrinkage. As such, the glycol-based G2 was selected as the final shrinkage reducing material for development of the highperformance shrinkage reducing agent.

3.2. Performance Enhancement of Shrinkage Reducing Materials. Concrete application tests showed that the glycolbased G2 was the most outstanding shrinkage reducing material in terms of fluidity and drying shrinkage reduction. However, G2 also showed some decrease in initial strength,

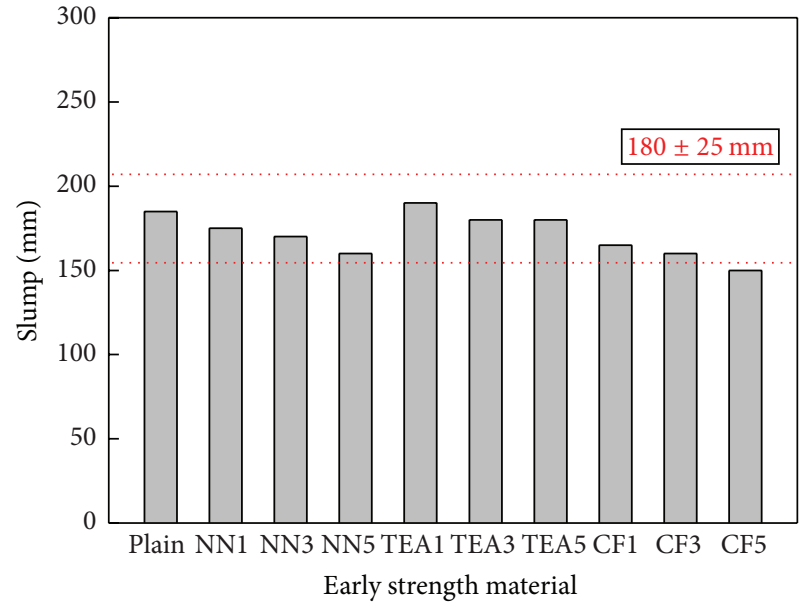

FIGURE 5: Slump of concrete in relation to the type and amount of early strength material.

and certain ancillary materials had to be added to improve performance. The materials added were $\mathrm{NN}\left(\mathrm{NaNO}_{3}\right)$, TEA (triethanolamine), and CF (calcium formate); concrete properties were analyzed in relation to the type and amount of early strength material.

Figure 5 shows the slump of concrete in relation to the type and amount of early strength material for the glycolbased material. With the exception of CF 5\%, all mixtures satisfied the target slump of $180 \pm 25 \mathrm{~mm}$, and fluidity decreased with increasing dosage of ancillary materials due to their specific characterization. TEA had results similar to those of the plain mixture and is expected to show no significant effect on the fluidity of concrete. NN, the most widely used early strength material, exhibited satisfactory performance but not as good as that of TEA.

The air content of concrete in relation to the type of early strength material is shown in Figure 6. Air content decreased 


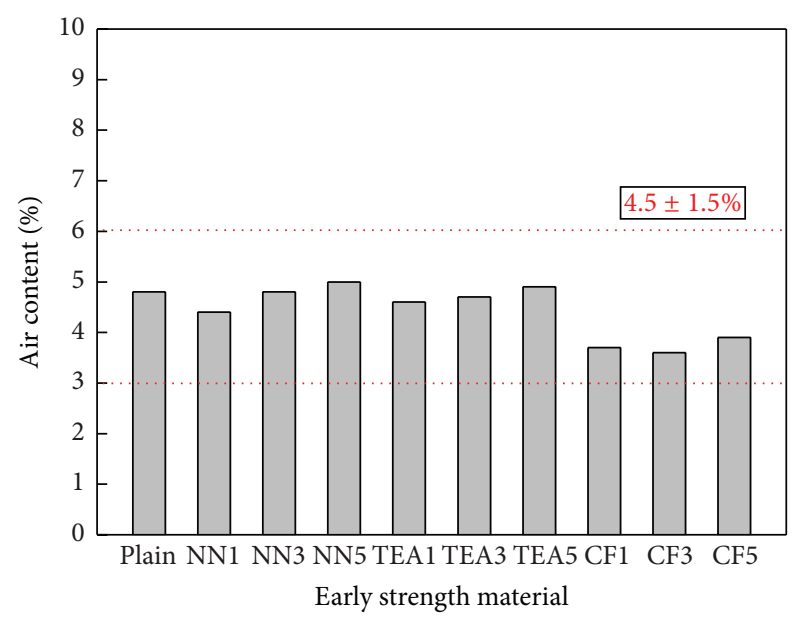

FIGURE 6: Air content of concrete in relation to the type and amount of early strength material.

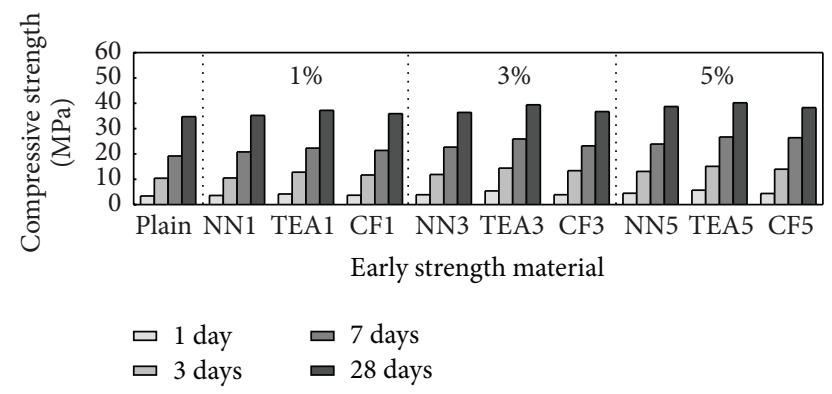

FIGURE 7: Compressive strength of concrete in relation to the type and amount of early strength material.

with increasing amount of early strength material, but the difference was not significant.

The compressive strength of concrete by age in relation to the type and amount of early strength material was shown in Figure 7. The compressive strength of concrete can be seen to have improved compared to that of the plain mixture. The strength was enhanced with increasing amount of early strength material. When the amount of material was $1 \%$ on day $1, \mathrm{NN}$ had higher compressive strength than the plain mixture by $0.2 \mathrm{MPa}$, TEA by $0.8 \mathrm{MPa}$, and $\mathrm{CF}$ by $0.3 \mathrm{MPa}$. On day 28 , the strength improvements were $0.5,2.5$, and 1.2 $\mathrm{MPa}$, respectively. The compressive strength of glycolbased shrinkage reducing materials without any addition of early strength materials was $80 \%$ compared to that of the plain mixture. The introduction of TEA improved the strength to $120 \%$ compared to that of the plain mixture. When the amount of early strength material was $3 \%$, TEA had higher strength by $2.0 \mathrm{MPa}$ on day $1,3.9 \mathrm{MPa}$ on day 3, 6.7 MPa on day 7, and 4.7 MPa on day 27. NN and CF showed slight improvements in strength, but not as much as that of TEA. When the amount of early strength material was 5\%, the improvement in strength was less than 3\%. Considering the possible changes in fluidity and air content at $5 \%$, this study selected TEA at 3\% for the development of the highperformance shrinkage reducing agent.

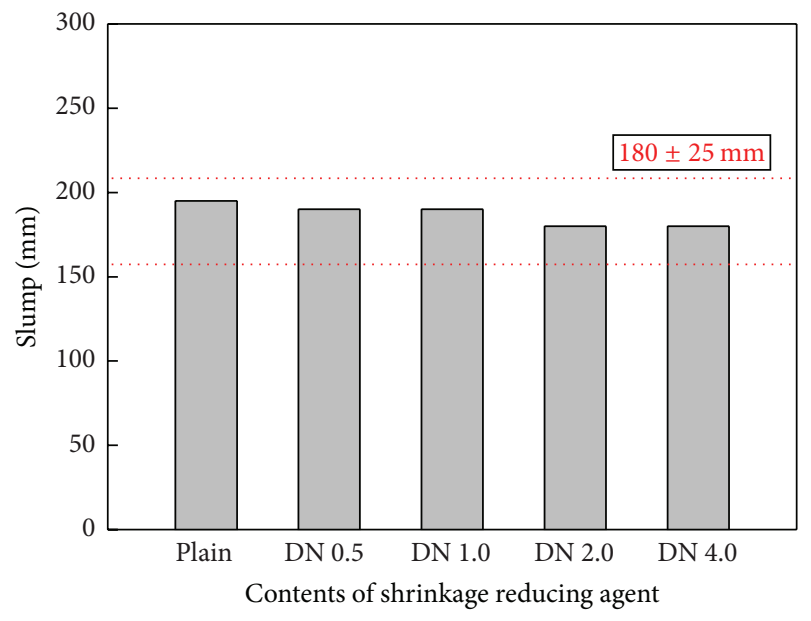

FIgURE 8: Relationship between slump and amount of shrinkage reducing agent.

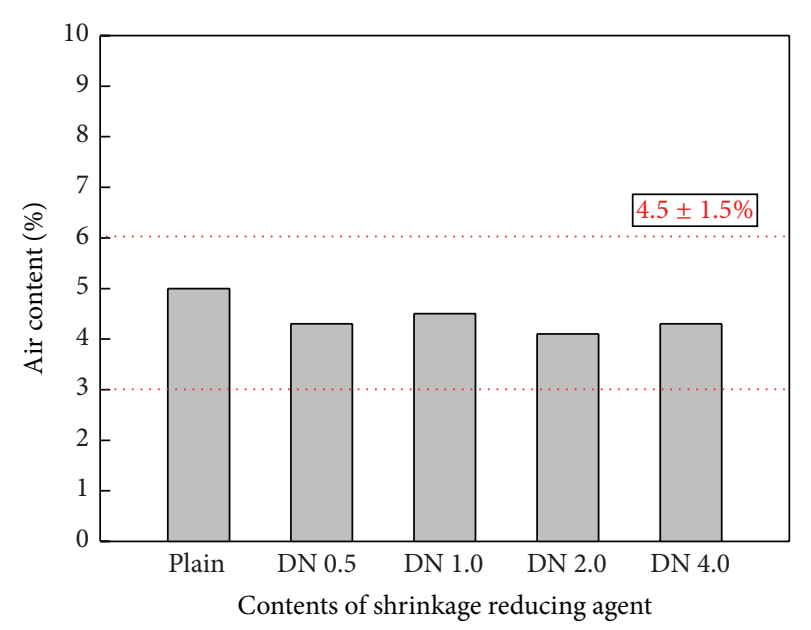

FIGURE 9: Relationship between air content and amount of shrinkage reducing agent.

3.3. Characteristics of Concrete Produced with High-Performance Shrinkage Reducing Agent (Performance Assessment of High-Performance Shrinkage Reducing Agent). To assess the performance of the developed high-performance shrinkage reducing agent and to determine the optimal amount, the effects on concrete were analyzed at varying unit powder contents of $0,0.5,1.0,2.0$, and $4.0 \%$.

Figure 8 shows the relationship between slump and amount of shrinkage reducing agent. Until 1.0\%, the results are similar to that of the plain mixture. Slight decreases in slump are observed at 2.0 and $4.0 \%$. These can be explained by the reduced fluidity arising from the decrease in mixing water at higher unit content of the shrinkage reducing agent. When the shrinkage reducing agent is at a level of $2.0 \%$ or higher, it is necessary to adjust the unit content or use an additional water-reducing agent.

Figure 9 shows the relationship between air content and amount of shrinkage reducing agent. The air content of the plain mixture at $5.0 \%$ satisfied the target range. Depending 


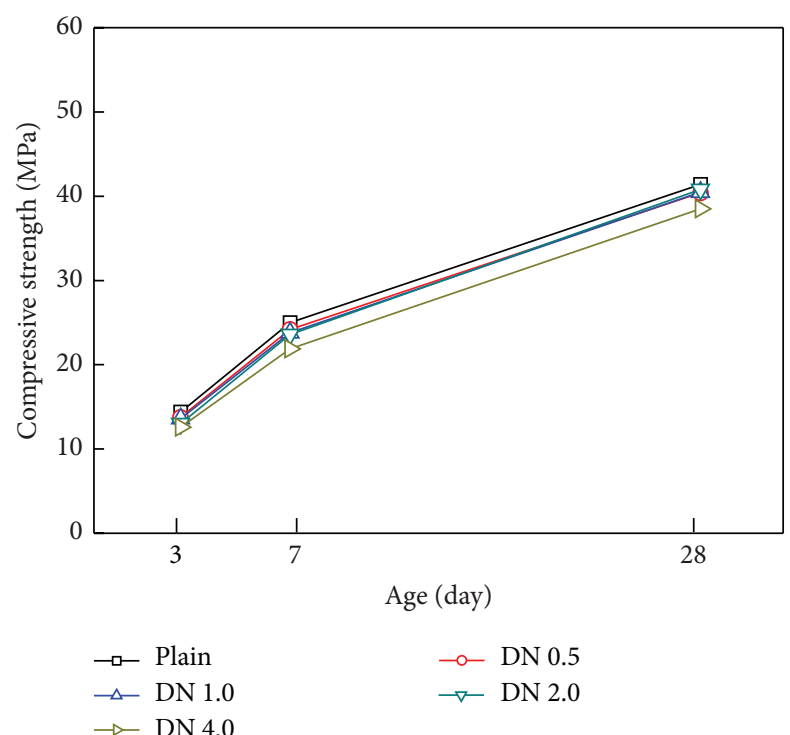

FIGURE 10: Compressive strength by age for varying amounts of shrinkage reducing agent.

on the amount of shrinkage reducing agent, there was a slight decrease in air content, but the target air content of $4.5 \pm 1.5 \%$ was satisfied in all cases. The decrease in air content due to the use of the shrinkage reducing agent can be traced to the decrease in viscosity; this is not significantly related to the variation in amount.

Figure 10 shows the compressive strength by age for varying amounts of shrinkage reducing agent. In Figure 10, the compressive strength of the plain mixture without any shrinkage reducing agent was $14.4 \mathrm{MPa}$ on day 3 and $41.4 \mathrm{MPa}$ on day 28 . The mixture with $2.0 \%$ shrinkage reducing materials had compressive strength equivalent to $80 \%$ of that of the plain mixture. When combined with the early strength material TEA, the strength in the early days was $90 \%$ of that of the plain mixture and remained similar to that of the plain mixture in the long term.

Some decrease in strength was observed with increasing amount of shrinkage reducing agent. On day 3 , the strength values were $97,95,90$, and $87 \%$ at $0.5,1.0,2.0$, and $4.0 \%$, respectively. The difference grew smaller as the days progressed. On day 28 , the strength was $98,98,99$, and $93 \%$ at 0.5 , $1.0,2.0$, and $4.0 \%$. When the amount of shrinkage reducing agent was $4.0 \%$, there was a slight decrease in strength. The strength was $87 \%$ in the early days and rose to $90 \%$ in the long term. However, sufficient review is needed before using the shrinkage reducing agent at $4.0 \%$. No special consideration is needed when the amount is less than $2.0 \%$.

Figure 11 shows the change in drying shrinkage length in relation to the amount of shrinkage reducing agent. In Figure 11, the drying shrinkage length of the plain mixture change can be seen to converge around day 40 and recorded a value of $760 \times 10^{-6}$ on day 56 . When the high-performance shrinkage reducing agent was used, there was less drying shrinkage length change compared to that present for the plain mixture. The drying shrinkage length change decreased

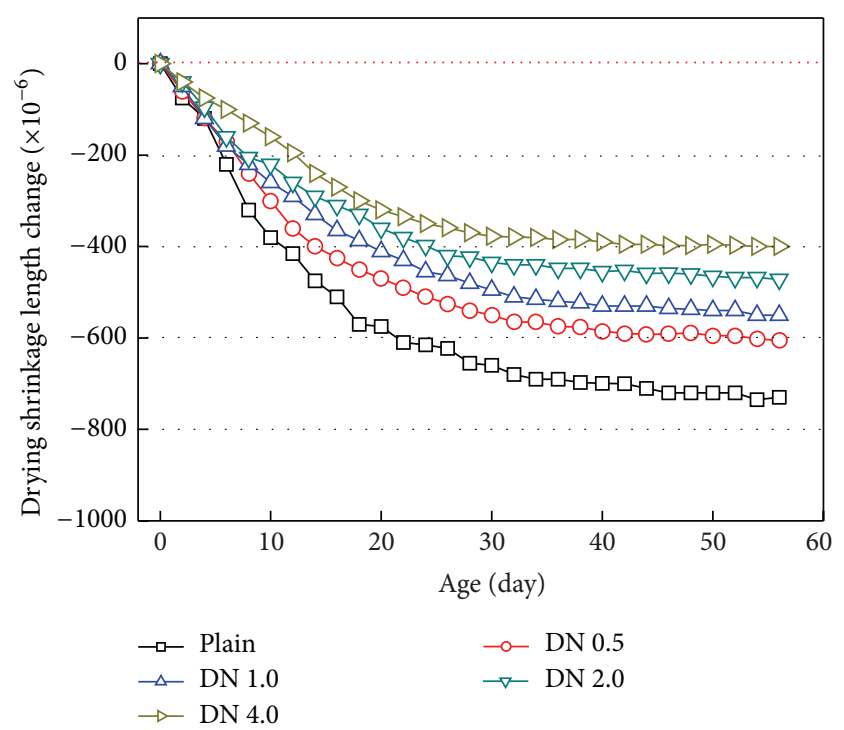

FIGURE 11: Drying shrinkage length change by age for varying amounts of shrinkage reducing agent.

with increasing amount of shrinkage reducing agent. With a value of $0.5 \%$ on day 56 , the drying shrinkage length change was $605 \times 10^{-6}$, which is a decrease of about $20 \%$. When the amount of high-performance shrinkage reducing agent was $2.0 \%$, the amount of shrinkage reduction was $40 \%$ compared to that of the plain mixture. While the effect was more prominent at higher amounts, to prevent the deterioration of the compressive strength and the other physical properties, the recommended amount is less than $2.0 \%$.

\section{Conclusion}

To ensure domestic production of shrinkage reducing agents, this study performed concrete application tests using various shrinkage reducing materials and developed a highperformance shrinkage reducing agent based on the selected material. The following conclusions were derived.

(1) Fluidity and air content were satisfactory for the various shrinkage reducing materials. The decrease in viscosity was the lowest for glycol-based materials. The compressive strength was in the order of plain $\rightarrow$ glycol-based $\rightarrow$ alcohol-based. Measurement of length changes showed that glycol-based materials had the best shrinkage control, and this was in the order of glycol-based $\rightarrow$ alcohol-based $\rightarrow$ plain. Glycol-based materials can serve as shrinkage reducing agents if the issue of strength decrease is resolved.

(2) When 3\% triethanolamine was used for early strength improvement, the strength was enhanced by $158 \%$ compared to that of the plain mixture on day 1, 135\% on day 7 , and $113 \%$ on day 28 .

(3) The amount of shrinkage reduction for the $2.0 \%$ shrinkage reducing agent was $40 \%$ of the value of the plain mixture. While the effect was more prominent at 
higher amounts, to prevent deterioration of the compressive strength and the other physical properties, the recommended amount is less than $2.0 \%$.

(4) Drying shrinkage can be reduced without affecting the compressive strength by using $3 \%$ triethanolamine for early strength improvement and a $2.0 \%$ glycol-based shrinkage reducing agent.

\section{Competing Interests}

The authors declare that they have no competing interests.

\section{Acknowledgments}

This work was supported by the Power Generation \& Electricity Delivery Department of the Korea Institute of Energy Technology Evaluation and Planning (KETEP) through a grant funded by the Korean Government Ministry of Trade, Industry \& Energy (no. 20131010501790).

\section{References}

[1] M. C. Han and D. G. Lee, "Strength and autogenous shrinkage of high strength mortar using water substituting liquid," Journal of the Korea Institute of Building Construction, vol. 11, no. 6, pp. 538-546, 2011.

[2] C. G. Han, M. C. Han, and D. G. Lee, "Added AE water reducing agent on physical properties of the concrete," Journal of Structural and Construction Engineering, vol. 2, no. 27, pp. 9198, 2008.

[3] N. J. Gardner and M. J. Lockman, "Design provisions for drying shrinkage and creep of normal-strength concrete," ACI Materials Journal, vol. 98, no. 2, pp. 159-167, 2001.

[4] C. de Sa, F. Benboudjema, M. Thiery, and J. Sicard, "Analysis of microcracking induced by differential drying shrinkage," Cement and Concrete Composites, vol. 30, no. 10, pp. 947-956, 2008.

[5] Z. P. Bazant and S. Baweja, "Creep and shrinkage prediction model for analysis and design of concrete structures: model B3," ACI Special Publications 194, 2000.

[6] I. Maruyama and A. Sugie, "Numerical study on drying shrinkage of concrete affected by aggregate size," Journal of Advanced Concrete Technology, vol. 12, no. 8, pp. 279-288, 2014.

[7] T. Ayano and F. H. Wittmann, "Drying, moisture distribution, and shrinkage of cement-based materials," Materials and Structures, vol. 34, no. 247, pp. 134-140, 2002.

[8] K. Eguchi and K. Teranishi, "Prediction equation of drying shrinkage of concrete based on composite model," Cement and Concrete Research, vol. 35, no. 3, pp. 483-493, 2005.

[9] M. H. Zhang, C. T. Tam, and M. P. Leow, "Effect of water-tocementitious materials ratio and silica fume on the autogenous shrinkage of concrete," Cement and Concrete Research, vol. 33, no. 10, pp. 1687-1694, 2003.

[10] M. C. Han, "Estimation of the autogenous shrinkage of the high performance concrete containing expansive additive and shrinkage reducing agent," Journal of the Korea Institute of Building Construction, vol. 7, no. 3, pp. 123-130, 2007.

[11] B. Rongbing and S. Jian, "Synthesis and evaluation of shrinkagereducing admixture for cementitious materials," Cement and Concrete Research, vol. 35, no. 3, pp. 445-448, 2005.
[12] F. Rajabipour, G. Sant, and J. Weiss, "Interactions between shrinkage reducing admixtures (SRA) and cement paste's pore solution," Cement and Concrete Research, vol. 38, no. 5, pp. 606615, 2008.

[13] J.-J. Park, D.-Y. Yoo, S.-W. Kim, and Y.-S. Yoon, "Drying shrinkage cracking characteristics of ultra-high-performance fibre reinforced concrete with expansive and shrinkage reducing agents," Magazine of Concrete Research, vol. 65, no. 4, pp. 248256, 2013. 

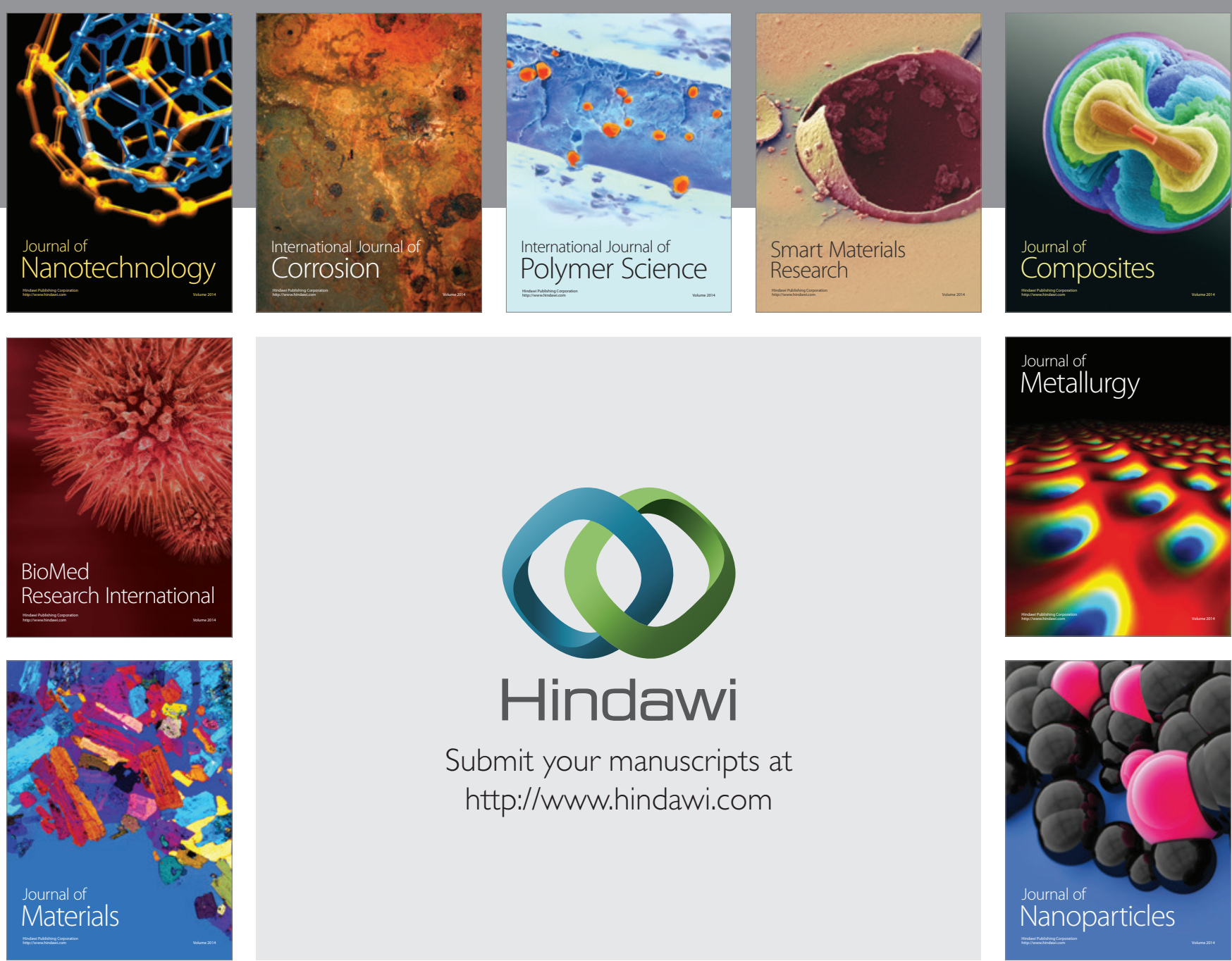

\section{Hindawi}

Submit your manuscripts at

http://www.hindawi.com

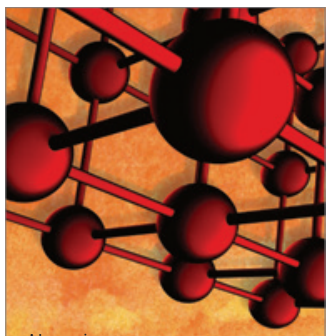

Materials Science and Engineering
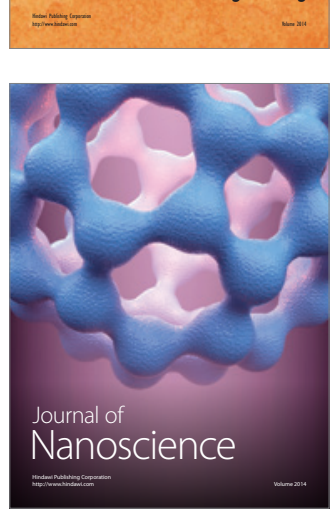
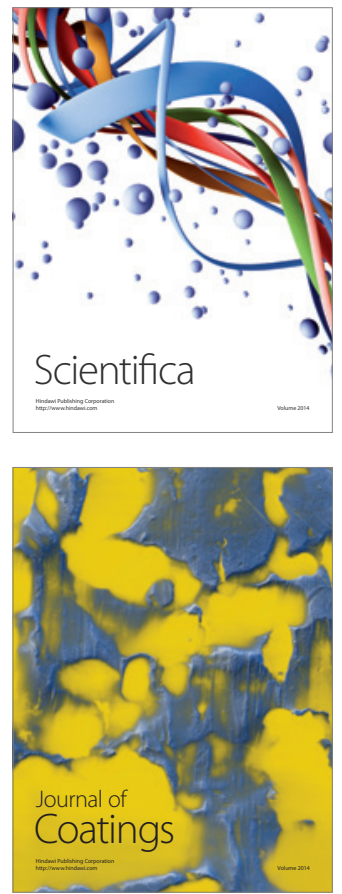
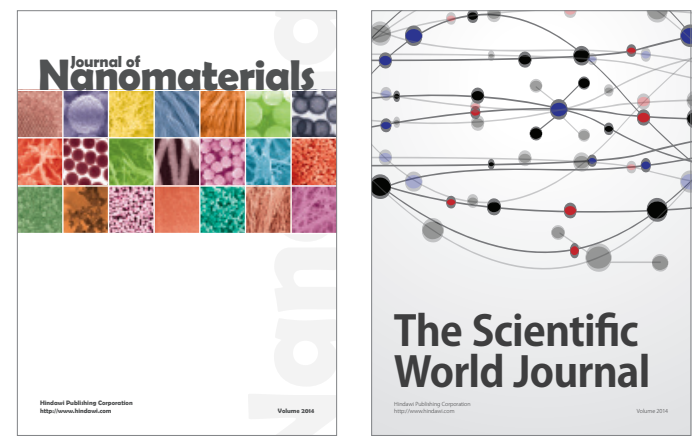

The Scientific World Journal
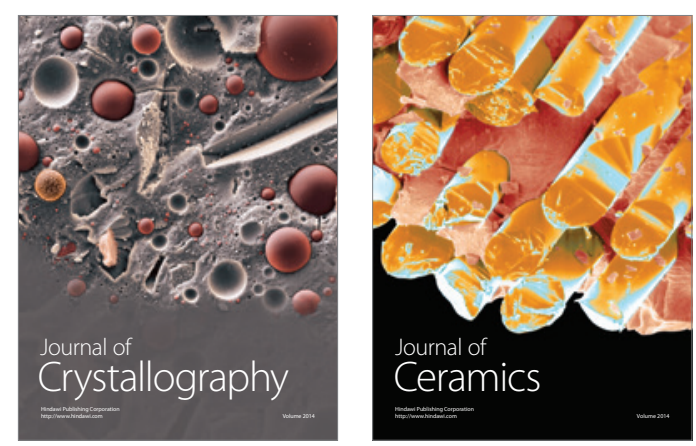
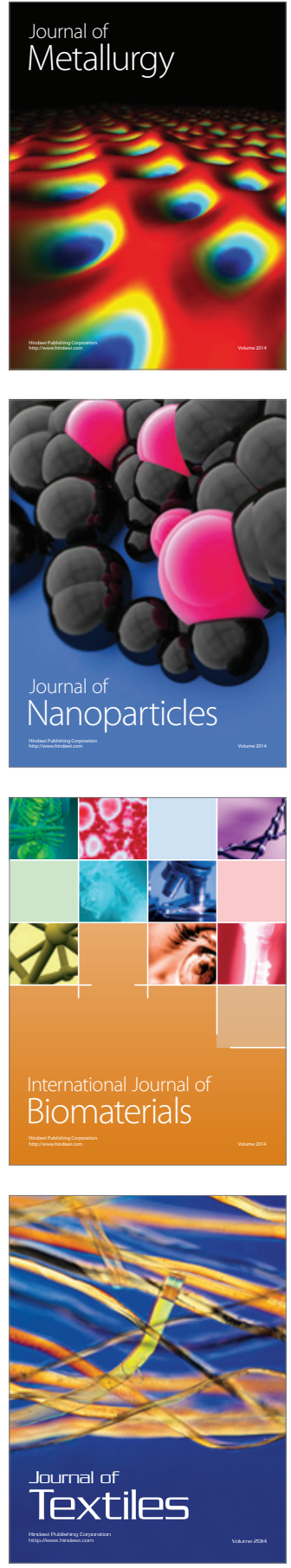